\title{
Molecular Cloning of Canine Excitatory Amino Acid Transporter 5 and Its Detection in Primary Lens Epithelial Cells
}

\author{
Hideharu OCHIAI $^{1)}$, Miyoko SAITO ${ }^{2)}$, Takuya MARUO ${ }^{3)}$, and Nobuyuki KANEMAKI ${ }^{3)}$ \\ ${ }^{1)}$ Research Institute of Biosciences, ${ }^{2)}$ Laboratory of Veterinary Surgery 2, and \\ ${ }^{3)}$ Veterinary Teaching Hospital, Azabu University, School of Veterinary Medicine, \\ 1-17-71 Fuchinobe, Sagamihara, Kanagawa 229-8501, Japan
}

\begin{abstract}
The full-length cDNA sequence of canine excitatory amino acid transporter (EAAT) 5 was determined in samples taken from the canine retina. The sequence was 2,467 bp long and was predicted to encode the 560 amino acid polypeptides. The deduced amino acid sequence of canine EAAT5 showed similarities of 91.8 and $92.7 \%$ to those of humans and rats, respectively. In canine, EAAT5 has a $49.4 \%$ identity with EAAT1, 43.7\% with EAAT2, 46.4\% with EAAT3, and $45.7 \%$ with EAAT4. RT-PCR analysis revealed EAAT5 expression in primary lens epithelial cell culture and the cerebellum, and Western blot analysis detected a single band of $60 \mathrm{kDa}$ which confirmed EAAT5 protein expression in these cells. In addition, all subtypes of EAAT were detected in canine lens epithelial cells, indicating the pivotal role of EAATs in supplying glutamate, the precursor of antioxidant glutathione in the lens.
\end{abstract}

Key words: amino acid transporter, cDNA sequence, dog, retina

\section{Introduction}

Excitatory amino acid transporters (EAATs) possess a Na-dependent high affinity for glutamate and play an important role in preventing the accumulation of the excitatory neurotransmitter in the synaptic cleft, which would cause over-stimulation of the receptors and neurodegeneration $[1,5,13,19]$. The EAAT gene family is comprised of 5 isoforms of the glutamate/aspartate transporter (EAAT1-EAAT5). EAAT1 is a ubiquitous subtype, and EAAT2, EAAT3, and EAAT4 are located primarily in the central nervous system, whereas EAAT5 is basically restricted to the retina.

Cataracts are among the most frequent ophthalmo- logical diseases seen in veterinary clinics. Dogs in particular are more prone to develop lens opacity than other domestic animals. Oxidative stress of lens constituents has been recognized as an important mechanism in the development of cataracts. Primary defenses that directly protect the lens against oxidative damage include small molecular antioxidants such as vitamin $\mathrm{C}$ and glutathione (GSH). The lens tissue consists of hundreds of layers of densely-packed lens fiber cells that have lost their nuclei and major cell organelles but are rich in crystallins and GSH for transparency [2]. GSH is a tripeptide synthesized from cysteine, glutamate and glycine by the sequential actions of the enzymes $\lambda$ glutamylcysteine synthetase and glutathione synthetase

(Received 25 October 2009 / Accepted 8 January 2010)

Address corresponding: H. Ochiai, Research Institute of Biosciences, Azabu University, 1-17-71 Fuchinobe, Sagamihara, Kanagawa 229-8501, Japan 
[20]. GSH principally acts to protect the thiol groups of proteins and minimize disulfide bond cross-linkages. In the lens, GSH is maintained at an unusually high concentration as result of potent synthesis from 3 precursor amino acids. Therefore, active transport of these amino acid into lens cells is essential for protecting the crystalline proteins from oxidative stress which causes lens opacity and eventually development of cataract. In the retina, the defective function or deranged regulation of EAAT-mediated transmitter re-uptake is considered to participate in retinopathies such as glaucoma [7].

Until now, only human, rodent, and salamander EAAT5 have been successfully cloned [1], and that of canine remains to be determined in spite of the importance of EAATs in veterinary ophthalmological pathogenesis. In the present study, we determined the nucleotide sequence of canine EAAT5 cDNA, and the deduced amino acid sequence was compared with those to reported of other animals. In addition, the expression of EAAT5 was examined in various canine organs, and the 5 subtypes of EAAT expression were investigated in lens epithelial cells (LEC) as a first step in exploring the physiological roles of EAAT5 in the canine lens.

\section{Materials and Methods}

\section{Determination of cDNA sequence of canine EAAT5}

All experiments were performed according to the guidelines of The Laboratory Animal Care Committee of Azabu University, and were in compliance with The Japanese Animal Welfare Guide. Total RNA was isolated from the retina of a healthy adult male dog using a RNA extraction solution (Isogen, Nippon Gene, Tokyo, Japan). The primers used for the amplification of partial canine EAAT5 cDNA were prepared from the region sequences conserved between humans and rats (s-1, a-1; Table 1). RT-PCR amplification was performed employing a SuperScript first cDNA system kit (Invitrogen, Carlsbad, CA, USA) with Hot start Ex Taq DNA polymerase (Takara, Kyoto, Japan). The band was excised from the agarose gel and purified using a NucleoTrap Gel Extraction kit (Genetics Japan, Tokyo, Japan). The extracted and purified DNA was cloned into a pCR II-TOPO cloning vector (Invitrogen) and sequenced with a BigDye terminator kit ver.3 (Applied Biosystems, Carlsbad, CA,
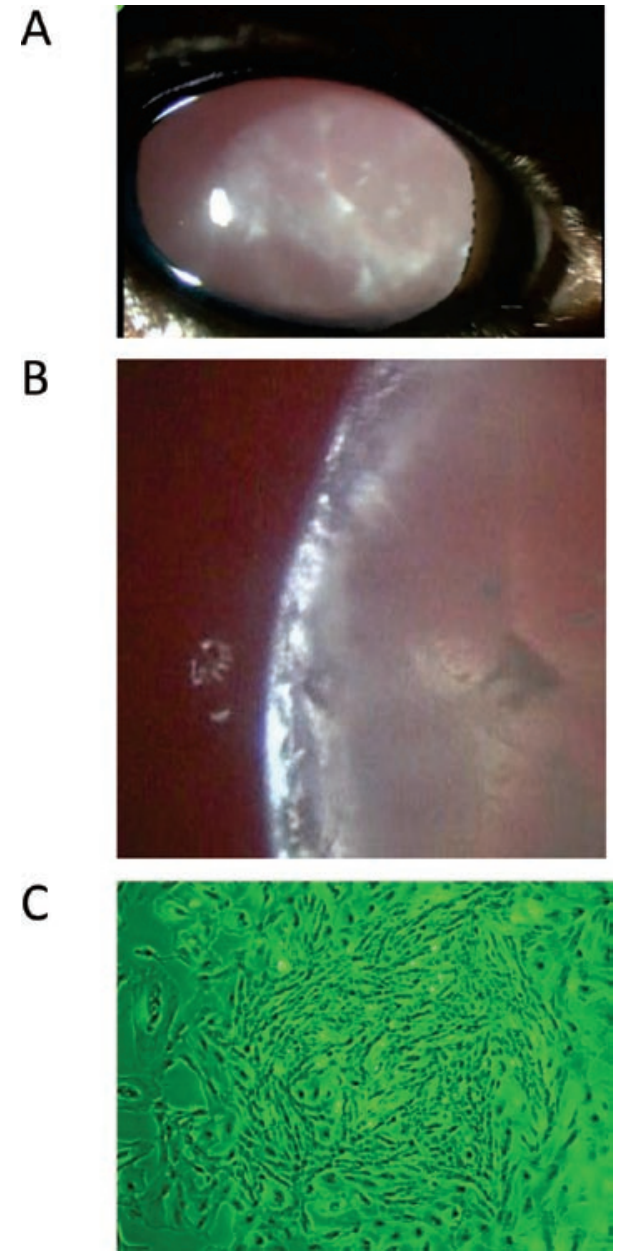

Fig. 1. Photographs of a Toy poodle dog presenting a mature cataract (A) and a slit-lamp photograph of the dog (B). Epithelial morphology in primary lens epithelial cells from the dog presented a mature cataract. The cells were seeded in a $30-$ mm chamber, and morphology was examined by phase-contrast microscopy at $\times 40$ magnification. The primary culture was proliferative and reached confluence after 3 days, though these cells ceased proliferation after passage $3(\mathrm{C})$.

USA). In order to determine the 3' and 5' regions of cDNA, RACE methods were carried out using a SMART RACE cDNA amplification kit (Clontech, Mountain View, CA, USA) and a set of canine EAAT5 gene-specific primers (GSP1 and GSP2: Table 1).

\section{Preparation of primary LEC culture}

An anterior capsulorrhexis specimen from a dog 
Table 1. Sequences of oligonucleotides used in this study

\begin{tabular}{lllc}
\hline Primer & \multicolumn{1}{c}{ Sequence (5'-3') } & Product (bp) \\
\hline Oligonucleotide for cloning of canine EAAT5 & 508 \\
s-1 & sense & AGCCACACTGCCCATCACCTTC & \\
a-1 & anti & CTCTTCACACAGCCATTCTGCTGG & \\
GSP1 for 3'RACE & sense & ATTAACGTGCTGGGTGATGCGCTGGCGG & \\
GSP2 for 5'RACE & anti & GGGCAATGCGCCGGTCGATGTGGTTGTT & \\
s-1 & sense & AGCCACACTGCCCATCACCTTC & 272 \\
a-2 & anti & GGTGAGCACGATGACCATGGTG & \\
Oligonucleotide for RT-PCR analysis of 5 isotypes of canine EAATs & 458 \\
Transcript & & & \\
EAAT1 & sense & ATTGTACAAGTGACAGCTGCAGACGCC & \\
(AF067847) & anti & TTTCCCTGCAATCAGGAAGAGGATGCC & \\
EAAT2 & sense & GCCATGGTGTATTACATGTCCACAACC & \\
(AF167076) & anti & CCATCCTTGAACTCCAAGCCCTTCTTG & \\
EAAT3 & sense & TGGGAAATATTCCGCAAGCTAGGCCTT & 214 \\
(AF167075) & anti & TTTCTTCTGCACAGCGGAAAGTGACAGG & \\
EAAT4 & sense & CACTCATTGTCTCCAGCCTGGTCACAG & 282 \\
(AF167077) & anti & TCTTGAACTGTTGAAGCAGGCCTCCA & \\
EAAT5 & sense & AGCCACACTGCCCATCACCTTC & 272 \\
(AB512464) & anti & GGTGAGCACGATGACCATGGTG & \\
GAPDH & sense & TGCTCCTTCTGCTGATGCCCCCAT & \\
(AB038240) & anti & TCTGGGTGGCAGTGATGGCATGGA & \\
\hline
\end{tabular}

(accession number) is indicated.

(3-year-old female Toy poodle) with naturally developing mature cataracts (Fig. 1A and 1B) was obtained prior to routine phacoemulsification cataract extraction. A small cut was made in the anterior capsule of the lens, a free edge was grasped with a forceps, and the capsule with its attached lens epithelium was placed in a 30-mm tissue culture dish (Corning Inc., Corning, NY, USA) immediately after the operation. LECs were basically prepared as described by Long [10]. After dispersing the cells by trypsin treatment, they were incubated in $2 \mathrm{ml}$ of Eagles's minimal essential medium (MEM) supplemented with $20 \%$ fetal calf serum and $50 \mu \mathrm{g} / \mathrm{ml}$ gentamycin. The culture was maintained at $37^{\circ} \mathrm{C}$ in a water-saturated air atmosphere containing $5 \% \mathrm{CO}_{2}$. Cell outgrowth was evident within 5 days of the initiation of the primary cultures, which were allowed to grow to confluence and sub-cultured for three to four passages.

RT-PCR analysis of EAAT5 mRNA in various canine tissues

In order to examine the expression of EAAT5 mRNA in various organs of the dog, we performed RT-PCR using newly designed primers specific to canine EAAT5 (s-1, a-2; Table 1). Total RNA samples were extracted from various tissues of a healthy dog, and RT-PCR was performed using the Super Script One-Step RT-PCR with Platinum Taq (Invitrogen) according to the manufacturer's instructions. The PCR condition was as follows: $55^{\circ} \mathrm{C} 30 \mathrm{~min}, 94^{\circ} \mathrm{C} 2 \mathrm{~min}$, and 40 cycles of $94^{\circ} \mathrm{C} 15 \mathrm{~s}$, $58^{\circ} \mathrm{C} 20 \mathrm{~s}$, and $72^{\circ} \mathrm{C} 20 \mathrm{~s}$.

RT-PCR analysis of EAAT1-5 mRNAs in primary culture of $L E C$

After isolation of total RNA from a primary culture of LEC, RT-PCR amplification was performed with primer set, s-1 and a-2, employing a SuperScript first cDNA system kit (Invitrogen) and Hot start Ex Taq DNA polymerase (Takara) under the following conditions: 25 cycles of at $94^{\circ} \mathrm{C} 10 \mathrm{~s}, 58^{\circ} \mathrm{C} 15 \mathrm{~s}$, and $72^{\circ} \mathrm{C} 60 \mathrm{~s}$. Primers used for the amplification of canine EAAT1-EAAT4 and GAPDH were prepared as described by Sato et al . [16] (Table 1). 
Western blot analysis of EAAT5 protein in various canine tissues

The membrane of each tissue was prepared for Western blot as reported by Denker et al. [6]. In brief, LEC or cerebellum was homogenized at $4{ }^{\circ} \mathrm{C}$ in the buffer containing $0.1 \mathrm{M} \mathrm{KCl}, 5 \mathrm{mM} \mathrm{Na}_{2} \mathrm{HPO}_{4} \mathrm{pH} 7.5,0.75 \mathrm{mM}$ Na-EGTA pH 7.5, 1 mM DDT, $5 \mathrm{mM} \mathrm{MgCl}{ }_{2}, 200 \mu \mathrm{g} / \mathrm{ml}$ phenylmethylsulfonyl fluoride, and $4 \mu \mathrm{g} / \mathrm{ml}$ leupeptin. Homogenates were centrifuged for $10 \mathrm{~min}$ to remove debris. The 1 unit volume of supernatant was laid over 3 unit volumes of sucrose solution containing $0.8 \mathrm{mM}$ sucrose and $2 \mathrm{mM}$ Na-EGTA and centrifuged at 32,000 $g$ for $40 \mathrm{~min}$. The protein concentration of the pellet was determined by the BCA method, and was used for western blot analysis. Membranes were solubilized, electrophoresed into $12 \%$ polyacrylamide gels, and immunoblotted with a chemiluminescence autoradiograph as previously described [12]. The protein bands in the SDSPAGE gel were transferred to a polyvinylidene difluoride membrane that was then treated with the primary antibody (rabbit anti-human EAAT5, $\times$ 50, Santa Cruz Biotechnology, Santa Cruz, CA, USA), followed by the secondary antibody [anti-rabbit IgG $(\mathrm{H}+\mathrm{L})$ goat IgG Fab' HRP, × 20,000, Seikagaku Corp., Tokyo, Japan]. The EAAT5 protein was detected with an ECL plus chemiluminescence detection system (GE Healthcare Bioscience) and exposed to an X-ray film.

\section{Results}

The LECs from a cataractous dog are shown in Fig. 1C. They maintained the epithelium morphology after 3 days of the first passage. Figure 2A shows the electrophoresis of RT-PCR products of canine EAAT5 using primers, $\mathrm{s}-1$ and a-1, that were prepared from the region sequences conserved between humans and rodents. The nucleotide sequence was 508 bp and showed a high similarity, 90\%, to the mouse EAAT5 cDNA sequence. The primers used for RACE were prepared from the sequence details listed in Table 1; 3'and 5'RACE products are also shown in Fig. 2B and 2C, respectively. The obtained nucleotide sequence (accession number AB512464) corresponding to a full-length canine EAAT5 cDNA was 2,467 bp in length and contained an entire open reading frame of 1,680 bp, which encoded canine

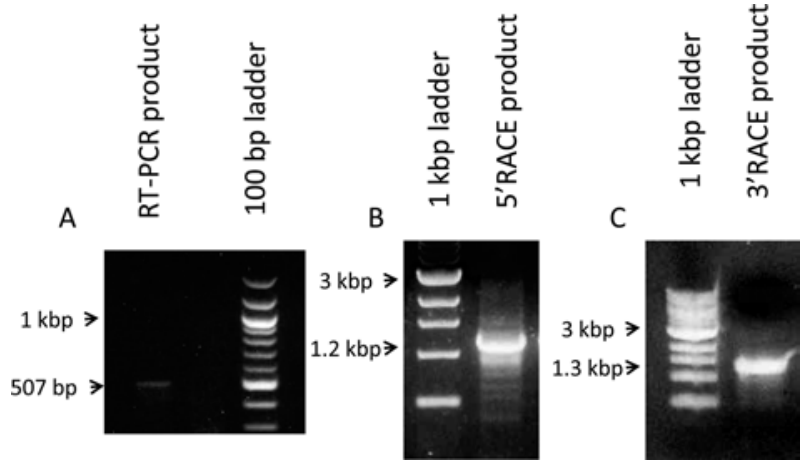

Fig. 2. PCR-based cloning of 5'- and 3'-stretched cDNA clones for canine EAAT5. The electrophoresis of RT-PCR products of canine EAAT5 using primers (s-1 and a-1) that are well conserved between humans and rodents (A). 5'and 3'RACE products with the primers shown in Table 1 are also shown in panels $\mathrm{B}$ and $\mathrm{C}$, respectively.

EAAT5 of 560 amino acids and had a theoretical mass of $61 \mathrm{kDa}$. Canine EAAT5, as found in humans, was one amino acid longer than that of mice. Figure 4 shows a comparison of canine EAAT5 with those reported for humans and rodents. The deduced amino acid sequence of EAAT5 showed high similarities, 91.8 and $92.7 \%$, to those of humans and mice, respectively. Like other members of this gene family, canine EAAT5 is similar to glycoprotein, but differs in that there is only a single $\mathrm{N}$-linked glycosylation site (N position; 191) in the putative large extracellular loop, while the other site $(\mathrm{N}$ position; 254) plays no part in glycosilation. In addition, the amino acid residues at the EAAT5 $\mathrm{C}$ terminus conform to a sequence motif found in the synaptic membrane proteins, E-S or T-X-V-COOH, as reported in other animals [17]. With optimal sequence alignment, canine EAAT5 exhibited 49.4\% identity with EAAT1, 43.7\% with EAAT2, 46.4\% with EAAT3, and $45.7 \%$ with EAAT4 (Fig. 5).

RT-PCR analysis of EAAT5 expression in canine tissues is shown in Fig. 6A. A single distinct band was observed only in the cerebellum. In addition, weak signals were detected in the cerebrum, kidney, spleen, testis, and heart; no signal was detected in other tissues studied. Figure 6 B shows the RT-PCR analysis of the five subtypes of EAAT in LECs. All subtypes of EAAT were present in canine LECs. The presence of EAAT5 protein in canine LECs was examined by Western blot 


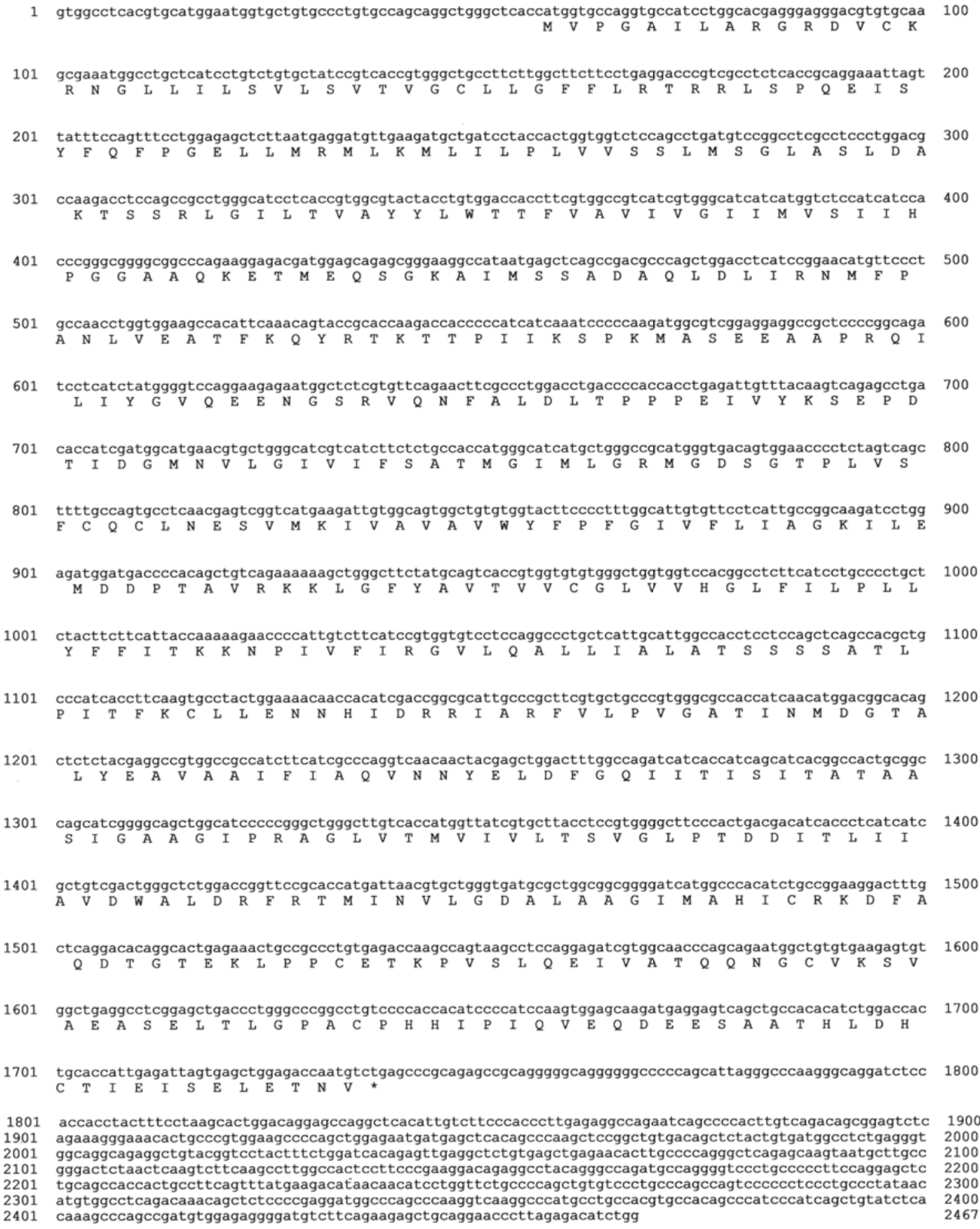

1601 ggctgaggectcggagetgaccetgggeccggcetgtccccaccacatcccatccaagtggagcaagatgaggagtcagctgccacacatctggaccac 1700

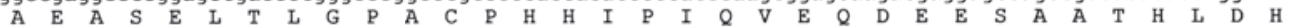

1701 tgcaccattgagattagtgagctggagaccaatgtctgagcccgcagagccgcagggggeaggggggccccagcattagggcccaagggcaggatctcc 1800 C T I E I S E L E T N V *

1801 accacctactttcctaagcactggacaggagccaggctcacattgtcttcccacccttgagaggccagaatcagcccacttgtcagacagcggagtctc 1900 1901 agaaagggaaacactgcccgtggaagccccagctggagaatgatgagctcacagcccaagctccggctgtgacagctctactgtgatggcctctgagggt 2000 2001 ggcaggcagaggctgtacggtcctactttctggatcacagagttgaggctctgtgagctgagaacacttgccccagggctcagagcaagtaatgcttgcc 2100 2101 gect 2100 2101 gggactctaactcaagtcttcaagccttggccactccttcccgaaggacagaggcctacagggccagatgccaggggtccctgcccccttccaggagctc 2200 2201 tgcagccaccactgccttcagtttatgaagacataacaacatcctggttctgccccagctgtgtccetgcccagccagtccccctccctgccctataac 230 2301 atgtggcctcagacaaacagctctccccgaggatggcccagcccaaggtcaaggcccatgcctgccacgtgccacagcccatcccatcagctgtatctca 2400 2401 caaagcccagccgatgtggagaggggatgtcttcagaagagctgcaggaacccttagagacatctgg

Fig. 3. Nucleotide and deduced amino acids of canine EAAT5 were shown. Full-length canine EAAT5 cDNA was 2,467 bp in length and contained an entire open reading frame of 1,680 bp, encoding canine EAAT5 of 560 amino acids. EAAT5 and had a theoretical mass of $61 \mathrm{kDa}$. The DDBJ accession number is AB512464. The termination codon is asterisked. 


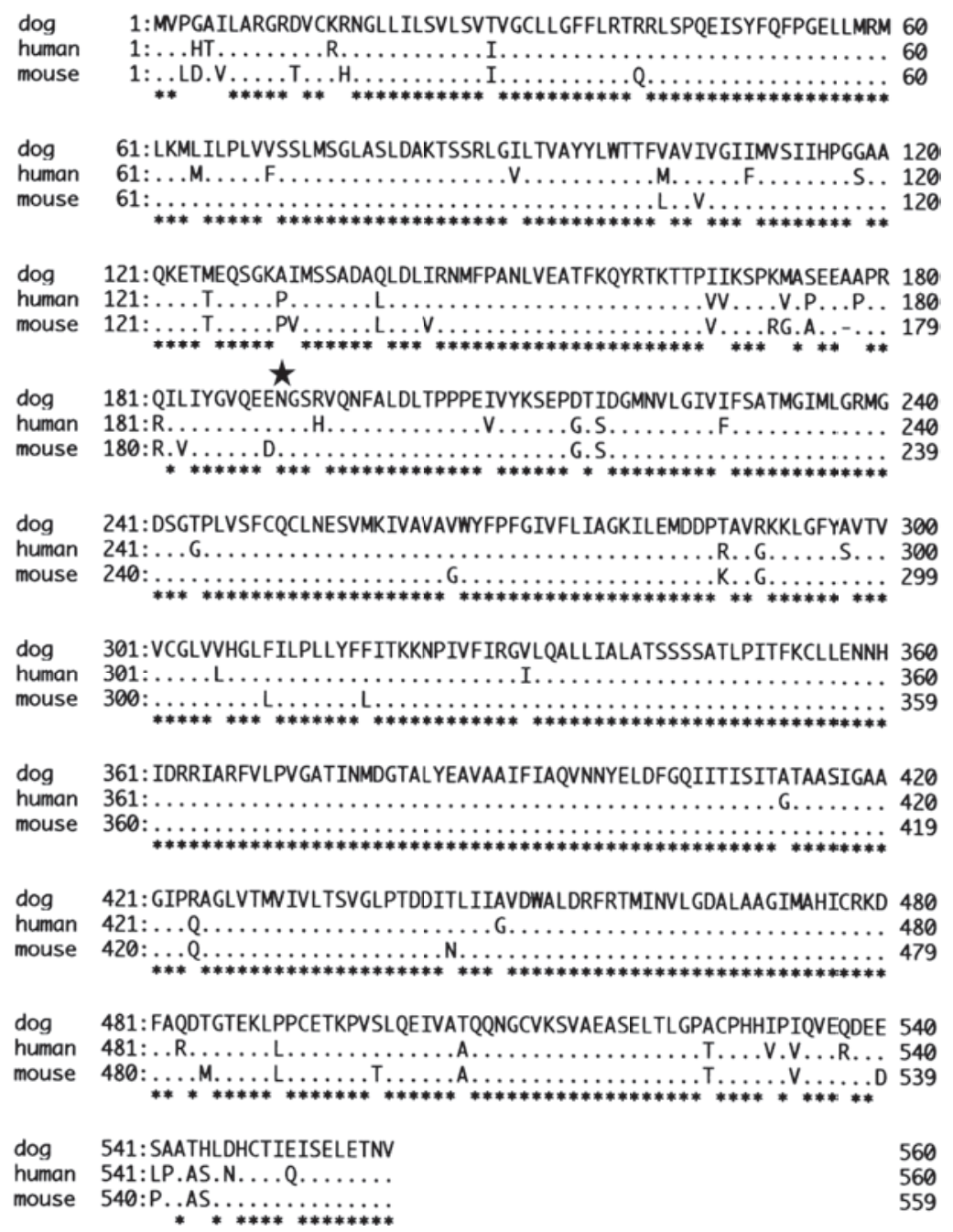

Fig. 4. Amino acid sequences of canine EAAT5 were compared with those of humans and rats. Multiple sequence alignments were performed using the Genetyx programme (ver 8). Asterisks and dots indicate identical residues and conservative substitutions, respectively. Potential glycosylation sites are indicated by a star.

analysis using anti-human EAAT5 antiserum (Fig. 7). A distinct single band at ca $60 \mathrm{kDa}$ was confirmed in the canine LECs and cerebellum.

\section{Discussion}

In this report, we determined the full-length cDNA sequence of canine EAAT5, which is the least known subtype of glutamate transporter, and examined its expression in various canine tissues. The sequence possesses a high homology with other EAAT5 reported in other animals, and the motif of the amino acid sequence was well conserved between mammalians. The sequence was 2,467 bp long and was predicted to encode 560 amino acid polypeptides. The deduced amino acid sequence of canine EAAT5 showed similarities of 91.8 and $92.7 \%$ to those of humans and rats, respectively. RTPCR analysis revealed signals in the primary cultures of LEC and cerebellum, and a single band of $60 \mathrm{kDa}$ was observed in Western blot analysis using anti-human EAAT5. In addition, all subtypes of EAAT were detected in canine LECs. The LECs are the progenitors of the lens fibers in vivo and undergo a developmental transition into fiber cells of the lens cortex, a process char- 


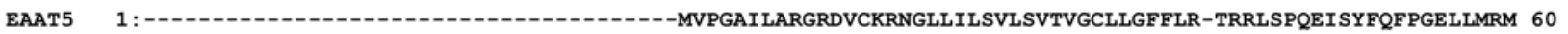
EAAT1 1:------MTKSNEEEPRTGGRMERFQRGVRKRTLLAKRKVQNITKEDVKSYLFRNAFVLLTVTAVIVGTILGFTLR-PYRMSYREVKYFSFPGELLMRM 91 EAAT2 1:--EAAT3 1:--- 3 (1:--1 EAAT4 1 :MSSHGNSLFLRESGQRLGRVGWLQRLQESLQQRALRTRLRLQTMTREHVLRFLRRNAFILLTVSAVVIGVSLAFALR-PYQLTYRQIKYFSFPGELLMRM 99

EAAT5 61:LKMLILPLVVSSLMSGLASLDAKTSSRLGILTVAYYLWTTFVAVIVGIIMVSIIHPGGAAOKETMEOSGKAI-MSSADAOLDLIRNMFPANLVEATFKOY 159 EAAT1 92: LQMLVLPLIISSLVTGMAALDSKASGKMGMRAVVYYMTTTIIAVVIGIIIVIIIHPGKGT-KENMHREGKIVQVTAADAFLDLIRNMFPPNLVEACFKQF 190 EAAT2 80:LKMLILPLIISSLITGLSGLDAKASGRLGTRAMVYYMSTTIIAAVLGVILVLAIHPGNPKLKKQLGPGKKNDEVSSLDAFLDLIRNLFPENLVQACFQQI 179 EAAT3 44:LSSLEKFYFAFPGEILMRMLKLIILPLIISSMITGVAALDSSVSGKIGLRAVIYYFCTTV-IAVVLGIVLVVSIKPGVSQKVDEIDRTGSSPEVSTVDAM 142 EAAT $100:$ LQMLVLPLIVSSLVTGMASLDNKATGRMGMRAAVYYMVTTVIAVFIGILMVTIIHPGKGS-KEGLHREGRIETIPTADAFMDLVRNMFPPNLVEACFKQF 198

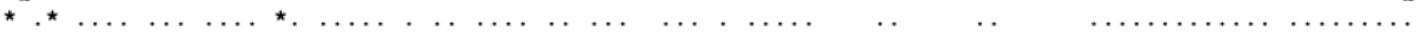

EAAT5 $160:$ RTKTTP--IIKSPKMASEEAAPRQILIYGVQEENGSRVQ-----NFALDLTPPPEIVYKSEPDTIDGMNVLGIVIFSATMGIMLGRMGDSGTPLVSFCQC 252 EAAT1 191: KTNYEKR-SFKVPIQSNETLMAAVINNVSEAMETLTRIT--------------EELIPVPGSVNGVNALGLVVFSMCFGLVIGNMKEQGQALREFFDS 273 EAAT2 180:QTVTKKV----LVAPPSDEDSNATNAVISLLNETVTEAPEEV------------KVVIKKGLEFKDGMNVLGLIGFFIAFGIAMGKMGEQAKLMVEFFNI 263 EAAT3 143: LDLIRNMFPENLVQACFQQYKTKREEVSSPSEPGMNMTEASVTAIMTTAISKNKTKEYKVVGMYSDGINVLGLIVFCLVFGLVIGKMGEKGQVLVDFFNA 242 EAAT4 199: KTQYSTRLVTRTIVRTENGSELGTSMPPPSSMDNGTSLLENVTWALGTLQEVLSFEETVPVPGSANGINALGLVVFSVAFGLVIGGVKHKGRVLRDFFDS 298

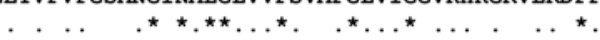

EAAT5 253: LNESVMKIVAVAVWYFPFGIVFLIAGKILEMDDPTAVRKKLGFYAVTVVCGLVVHGLFILPLLYFFITKKNPIVFIRGVLQALLIALATSSSSATLPITF 352 EAAT1 274 : LNEAIMRLVAVIMWYAPLGILFLIAGKIVEMEDMGVIGGQLAMYTVTVIVGLLIHAVIVLPLLYFLVTRKNPWVFIGGLLQALITALGTSSSSATLPITF 373 EAAT2 264 : LNEIVMKLVIMIMWYSPLGIACLICGKIIAIKDLEVVARQLGMYMITVIVGLIIHGGIFLPLIYFLVTRKNPFSFFAGIFQAWITALGTASSAGTLPVTF 363 EAAT 243 : LSDATMKIVQIIMCYMPLGILFLIAGKIIEVEDWEIF-RKLGLYMATVLSGLAIHSIIILPLIYFIVVRKNPFRFAMGMAQALLTALMISSSSATLPVTF 341

EAAT4 299: LNEAIMRMVGIIIWYAPVGILFLIAGKILEMEDMAVLGGQLGMYTLTVIVGLFLHAGGVLPLIYFLITHRNPFPFIGGVLQALITAMGTSSSSATLPITF 398

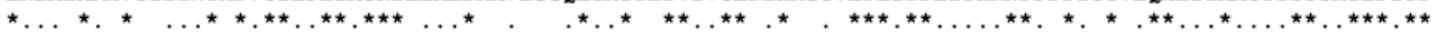
EAAT5 353: KCLLENNHIDRRIARFVLPVGATINMDGTALYEAVAAIFIAQVNNYELDFGQIITISITATAASIGAAGIPRAGLVTMVIVLTSVGLPTDDITLIIAVDW 452 EAAT1 374 : KCLEENNGVDKRVTRFVLPVGATINMDGTALYEALAAIFIAQVNNFELNFGQIITISITATAASIGAAGIPQAGLVTMVIVLTSVGLPTDDITLIIAVDW 473 EAAT2 364 : RCLEENLGIDKRVTRFVLPVGATINMDGTALYEAVAAIFIAQMNGVILDGGQIVTVSLTATLASVGAASIPSAGLVTMLLILTAVGLPTEDISLLVAVDW 463 EAAT3 342: RCAEEKNQVDKRITRFVLPVGATINMDGTALYEAVAAVFIAQLDGLDLGIGQIITISVTATAASIGAAGVPQAGLVTMVIVLSAVGLPPEDVTLIIAVDW 441 EAAT4 399: RCLEEGLGVDRRITRFVLPVGATVNMDGTALYEALAAIFIAQVNNYELNLGQITTISITATAASVGAAGIPQAGLVTMVIVLTSVGLPTEDITLIIAVDW 498

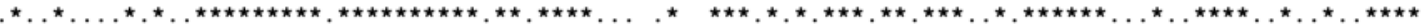
EAAT5 453 : ALDRFRTMINVLGDALAAGIMAHICRKDFAQDTGTEKLPPCETKPVSLQEIVATQQNGCVKSVAEASELTLGPACPHHIPIQVEQDEESAATHLDHCTIE 552 EAAT1 474 : FLDRLRTTTNVLGDSLGAGIVEHLSRHELKNRDIEMGNSVIEENEMKKPYQ-LIAQESETEKPTDSETKM------------------------------ 542 EAAT2 464 : LLDRMRTSVNVVGDSFGAGIVYHLSKSELDTIDSOHRVHEDIEMTKTOSIYDVKNLRESNSNOCVYAAHNSVIVDECKVTLAANGKSADCGVEEEPWKRE 563 EAAT3 442: LLDRFRTMVNVLGDAFGTGIVEKLSKKELEQMDVSSEVNIVNPFALESTILDNEDSDTKKSYVNGGFAVDKSDTISFTQTSQF----------------- 524 EAAT4 499: FLDRLRTMTNVLGDSIGAAVIEHLSQREL-----ELQEAELTLPSLGKPYKPLMAQEKGASRGRGGNESAM----------------------------- 564

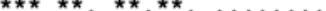

EAAT5 553: ISELETNV

EAAT1 542:------

EAAT2 $564: \mathrm{K}-------$

EAAT3 $524:------$

EAAT4 $564:-------$

Fig. 5. Predicted amino acid sequences of canine EAAT5 are shown in alignment with other known canine EAAT subtypes. In this alignment, amino acid residues identical in four of the five sequences are shown within the dotted area to illustrate the extensive amino acid conservation in this gene family.

acterized by distinct biochemical and morphologic changes such as the synthesis of crystalline proteins, cell elongation, loss of cellular organelles, and disintegration of the nucleus. It is recognized that the lens epithelium plays a pivotal role in the development and progression of cataracts, particularly those caused by exogenous stress. Therefore, it was suggested that primary damage to LEC causes abnormal differentiation of epithelial cells to lens fibers, eventually developing into opacity of the lens tissues. GSH is an essential antioxidant required for the maintenance of lens transparency. Among 3 precursor amino acids, glutamate concentration is particularly important for GSH levels. It was demonstrated that high glutamate concentration caused high level of GSH by the fact that feedback inhibition of $\lambda$-glutamylcysteine synthetase by glutathione was released by the high glu- tamate concentration in canine erythrocytes [11]. Lim et al. [9] reported the detection of EAAT1 to 5 by RTPCR in rat lens fiber cells, and found that EAAT expression was restricted to the outer cortex of the lens EAAT, while EAAT4/5 were the subtypes in cortical fiber cells and EAATs were absent from the core region. In this study, RT-PCR analysis revealed that the 5 subtypes of EAAT were present in canine LECs. GSH is the primary defense mechanism that directly protects the lens from oxidative damage. Therefore, a potent expression of glutamate transporters is needed to maintain a high GSH concentration to protect the lens from oxidative stress. Our results confirm the importance of EAATs in lens tissues. EAAT5 was originally identified from a human retina cDNA library, and its distribution was evaluated by Northern blot analysis; EAAT5 was pre- 


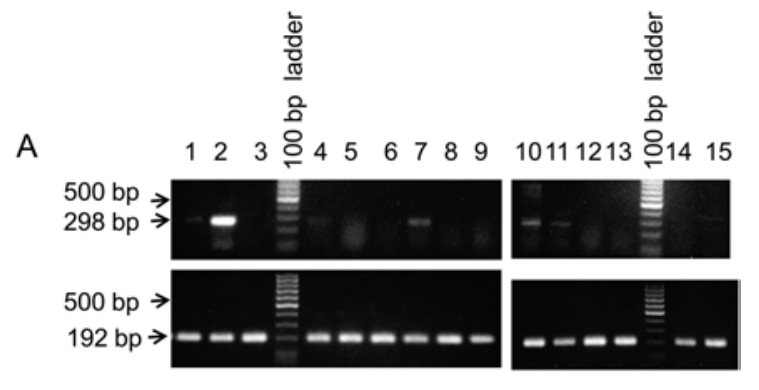

B

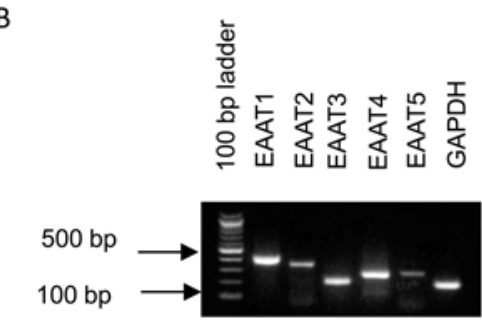

Fig. 6. (A) Detection of canine EAAT5 mRNA in various dog tissues. EAAT5 mRNA and glyceraldehyde-3phosphate dehydrogenase (GAPDH) were examined by RT-PCR techniques using primers specific to each cDNA indicated in Table 1. Lane 1: cerebrum; lane 2: cerebellum; lane 3: trachea; lane 4: kidney; lane 5: liver; lane 6: lung; lane 7: spleen; lane 8: salivary gland; lane 9: pancreas; lane 10: testis; lane 11: heart; lane 12: ileum; lane 13: colon; lane 14: bladder; lane 15: skeletal muscle. (B) RT-PCR analysis of 5 subtypes of glutamate transporters in LEC from a cataractous $\mathrm{dog}$.

dominantly expressed in the retina and weak signals were also detected in the liver and heart. In canine, RT-PCR analysis showed that signals were weak in the cerebrum, kidney, spleen, testis, and heart, though the significance of EAAT5 expression in these tissues remains uncertain. Western blot analysis using anti-human EAAT5 antiserum confirmed a distinct single band at $c a 60 \mathrm{kDa}$ both in the canine LEC and cerebellum (Fig. 7). As the theoretical mass of canine EAAT5 is $61 \mathrm{kDa}$, it was not likely to be glycosylated protein in these tissues in spite of possessing potential N-linked glycosylation site. EAAT5 localization in the retina has been reported in several mammals. Rod photoreceptor terminals are labeled with anti-EAAT5 antibody in all species, while expression in cone terminals has only been confirmed in cats [15]. Rod bipolar cell terminals as well as some cone bipolar cells were detected in the adult rat [14], while EAAT5 was not reported in the bipolar cells of

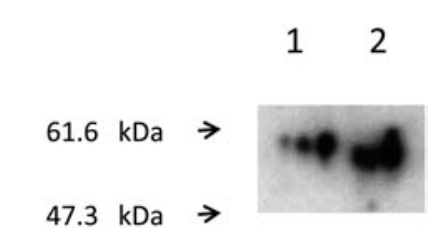

Fig. 7. Western blot analysis of canine EAAT5 expression in the cell membrane. Lane 1: $\operatorname{LEC}(50 \mu \mathrm{g})$; lane 2: cerebellum $(10 \mu \mathrm{g})$.

rabbit, macaque, and cat [6]. In the cat retina, some amacrine ganglion cells were labeled in addition to photoreceptors, while EAAT5 was expressed in the terminals of the cone and rod photoreceptors in mice. Transporter currents elicited by glutamate are largely carried by chloride ions, indicating that EAAT5 exhibits a prominent chloride conductance, and it has been suggested that the EAAT5-associated chloride conductance may play a role in visual processing [1]. Interestingly, it was reported that the lenticular antioxidant system differs markedly between dogs and other animals [18]. Therefore, in canine, the functional importance of EAAT5 may differ from other mammals. The localization of EAAT5 in the canine retina will be demonstrated in detail by preparing anti-canine EAAT5 serum based on the information clarified in this study. Recently, it was reported that the kinases SGK1 and SGK3 increase EAAT5 activity by increasing the cell surface abundance of the carrier [3], although the detailed regulation of EAAT5 still remains uncertain. cDNA sequence data and the tissue distribution of canine EAAT5 will contribute to the understanding of glutamate transport and metabolism in the canine eye.

\section{Acknowledgment}

This study was supported by a Grant-in-aid to HO from the Ministry of Education, Culture, Sports, Science and Technology of Japan.

\section{References}

1. Arriza, J., Eliasof, S., Kavanaugh, M.P., and Amara, S. 1997. Excitatory amino acid transorter 5, a retinal glutamate transporter coupled to a chloride conductance. Proc. Natl. Acad. Sci. U.S.A. 94: 4155-4160. 
2. Bhat, S.P. 2001. The ocular lens epithelium. Biosci.Rep. 21: 537-563.

3. Boehmer, C., Rajamanickam, J., Schniepp, R., Kohler, K., Wulff, P., Kuhl, D., Palmada, M., and Lang, F. 2005. Regulation of the excitatory amino acid transporter EAAT5 by the serum and glucocorticoid dependent kinases SKG1 and SKG3. Biochem. Biophys. Res. Commun. 329: 738742 .

4. Denker, B.M., Kwon, E.D., Kuhajda, F.P., and Agre, P. 1988. Identification, purification, and partial characterization of a novel $\mathrm{Mr}$ 28,000 integral membrane protein from erythrocytes and renal tubules. J. Biol. Chem. 263: 15634-15642.

5. Fairman, W.A., Vandenberg, R.J., Arriza, J.L., Kavanaugh, M.P., and Amara, S.G. 1995. An excitatory amino-acid transporter with properties of a ligand-gated chloride channel. Nature 375: 599-603.

6. Fyk-Kolodziej, B., Qin, P., Dzhagaryan, A., and Pourcho, R.G. 2004. Differential cellular and subcellular distribution of glutamaters in the cat retina. Vis. Neurosci. 21: 551565 .

7. Harada, T., Harada, C., Nakamura, K., Quiah, H.A., Okumura, A., Namekata, K., Saeki, T., Aihara, M., Yoshida, H., Mitani, A., and Tanaka, K. 2007. The potential role of glutamate transporters in the pathogenesis of normal tension glaucoma. J. Clin. Inv. 117: 1763-1770.

8. Kanai, Y. and Hedger, M.A. 1992. Primary structure and functional characterization of a high-affinity glutamate transporter. Nature 360: 467-471.

9. Lim, J., Lam, Y.C., Kisler, J., and Donaldson, P.J. 2005. Molecular characterization of the cystine/glutamate exchanger and excitatory amino acid transporters in the rat lens. Inv. Ophthal. Vis. Sci. 46: 2869-2877.

10. Long, A.C., Aglar, A., Colitz, C.M., Zhang, J., Hayek, M.G., Failla, M.L., and Bomser, J.A. 2008. Isolation and characterization of primary canine lens epithelial cells. Vet. Ophthal. 11: 38-42.

11. Maede, Y., Kasai, N., and Yaniguchi, N. 1982. Hereditary high concentration of glutathione in canine erythrocytes associated with high accumulation of glutamate, glutamine, and aspartate. Blood 59: 883-889.

12. Ochiai, H., Hishiyama, N., Hisamatsu, S., and Kanemaki, N. 2008. Aquaporin 1 expression in tissues of canines possessing inherited high $\mathrm{K}$ erythrocytes. J. Vet. Sci. 9: 203-205.

13. Pines, G., Danbolt, N.C., Bjoras, M., Zhang, Y., Bendahan, A., Eide, L., Koepsell, H., Storm, M.J., Seeberg, E., and Kannar, B.I. 1992. Cloning and expression of a rat brain L-glutamate transporter. Nature 360: 464-467.

14. Pow, D.V. and Barnett, N.L. 2000. Developmental expression of excitatory amino acid transporter 5 : a photoreceptor and bipolar cell glutamate transporter in rat retina. Neurosci. Lett. 280: 21-24.

15. Pow, D.V., Barnett, N.L., and Penfold, P. 2000. Are neuronal transporters relavant in retinal glutamate homeostasis? Neurochem. Int. 37: 191-198.

16. Sato, K., Inaba, M., Suwa, Y., Matsuu, A., Hikasa, Y., Ono, K., and Kagota, K. 2000. Inherited defects of sodiumdependent glutamate transport mediated by glutamate/ aspartate transporter in canine red cells due to a decreased level of transporter protein expression. J. Biol. Chem. 275: 6620-6627.

17. Sheng, M. 1996. PDZs and receptor/channel clustering: rounding up the latest suspects. Neuron 17: 575-578.

18. Slaughter, M.R., Thakkar, H., and O'Brien, P.J. 2003. Differential expression of the lenticular antioxidant system in laboratory animals: a determinant of species predilection to oxidative stress-induced ocular toxicity. Cur. Eye Res. 26: $15-23$.

19. Storck, T., Schulte, S., Hoffman, K., and Stoffel, W. 1992. Structure, expression and functional analysis of a Nadependent glutamate/aspartate transporter from rat brain. Proc. Natl. Acad. Sci. U.S.A. 89: 10955-10959.

20. Valencia, E., Marin, A., and Hardy, G. 2001. Glutathionenutritional and pharmacological viewpoint. Nutrition 17: $485-486$. 